\title{
Structural Aspects of Urethrovesical Function in the Female
}

\author{
John O.L. DeLancey \\ Department of Obstetrics/Gynecology, Division of Gynecology, University of Michigan \\ Hospitals, Ann Arbor
}

Urodynamic investigations have provided detailed physiologic information which raises morphologic questions not easily answered by older descriptions of urethral anatomy. This article describes urethrovesical structure specifically as it has to do with urodynamic evaluation of the lower urinary tract.

Key words: anatomy, urethra, urethral anatomy, urinary incontinence, urodynamics

\section{INTRODUCTION}

There have been a number of contributions to our understanding of the general structure of the female urethra and vesical neck as they have to do with urinary continence in women [Krantz, 1951; Ricci et al., 1950; Huisman, 1983; Gosling, 1985]. These anatomical observations have allowed us to understand many functional aspects of this region. As new measurement techniques are applied to this area, physiologic observations continue to be made which are not entirely explained by previous morphological descriptions. The intent of this article is to focus on the structural aspects of the urethrovesical unit as they have to do with urodynamic observations of lower urinary tract function, and as they relate to urinary incontinence. This report will consider how the anatomy of the lower urinary tract relates to its observed function.

The advent of fluoroscopically guided pressure measurements and miniaturized pressure transducers has made the determination of pressures in localized regions of the lower urinary tract possible, as well as permitting continuous observation of the mobility of the vesical neck and proximal urethra. This precisely localized functional information has raised the obvious question of where various structures are found along the length of the urethra. The author has examined the location of those tissues which may influence the urethra either by constricting its lumen or supporting its proximal portion [DeLancey, 1986], and this topographic organization will be used as a framework to discuss some morphological and functional aspects of this region.

Received for publication November 10, 1987; accepted July 18, 1988.

Address reprint requests to Dr. John O.L. DeLancey, Department of Obstetrics/Gynecology, Division of Gynecology, University of Michigan Hospitals, D2230 Medical Professional Building, 1500 East Medical Center Drive, Ann Arbor, MI 48109-0718. 


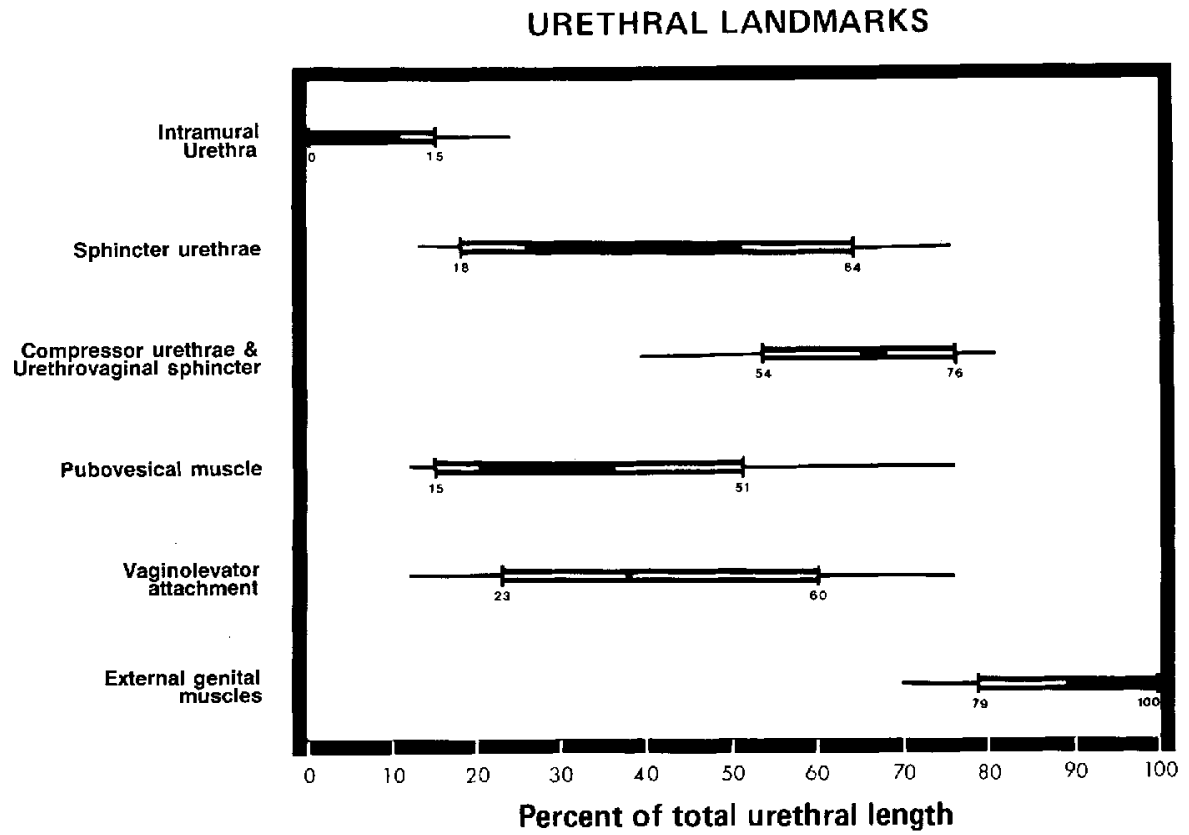

Fig. 1. Average spatial distribution of paraurethral structures as well as the range of values found. Compressor urethrae and urethrovaginal sphincter lie within the perineal membrane (= urogenital diaphragm). Reprinted with permission from the American College of Obstetricians and Gynecologists, Obstet Gynecol 68:91, 1986.

These observations have been made by examining serial histologic sections which were available through the courtesy of Dr. T.M. Oelrich who made them for his contribution on the striated urogenital sphincter [Oelrich, 1983]. The locations of these structures are displayed in Figures 1 and 2.

\section{LOCATION OF URETHRAL AND PARAURETHRAL STRUCTURES}

The overall organization of the vesical neck and urethra can be understood by considering this region to be divided into five equal portions, each consisting of roughly $20 \%$ of the total length of the urethral lumen (Table I), with the internal urinary meatus being the zero point, and the external meatus, $100 \%$ of urethral length. In this division, the uppermost one-fifth represents the intramural urethra, where the lumen traverses the bladder base and is surrounded by the tissues of the vesical neck. The next two-fifths of its length represent the midurethra. In this region is found the upper sphincteric portion of the striated urogenital sphincter muscle (sphincter urethrae), as well as the pubovesical muscle (= pubovesical ligament) which courses anterior to the urethra to join the vesical neck. Furthermore, the attachment of the vagina and paraurethral tissues to the muscle of the pelvic diaphragm (vaginolevator attachment) is found in this region. This attachment is to the pubococcygeus portion of the levator ani muscles which make up the pelvic diaphragm.

In the next region the urethra passes under the arch of the pubic bones, and is 


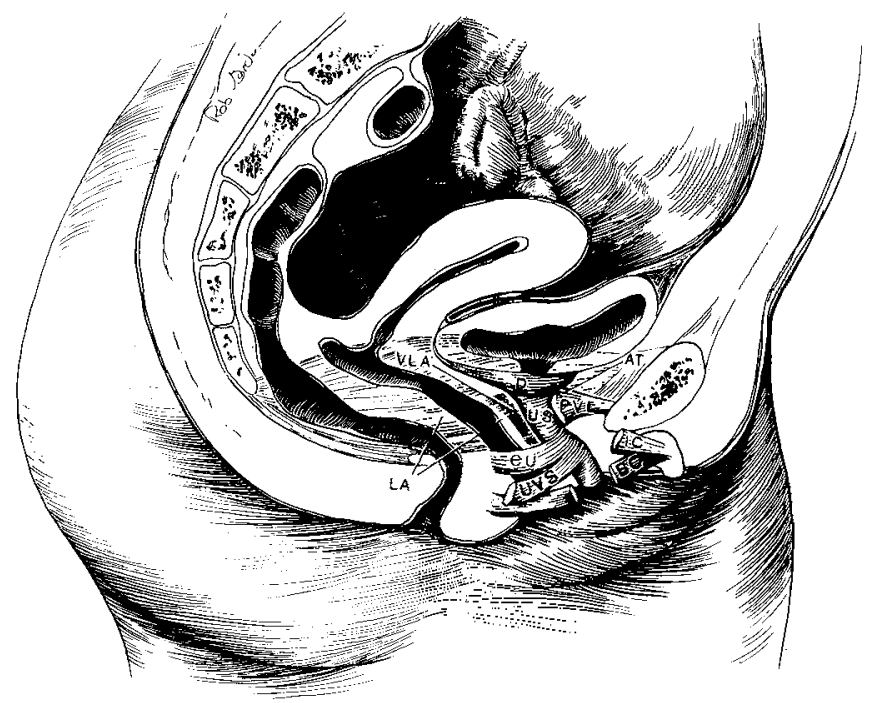

Fig. 2. Interrelationships and approximate location of paraurethral structures. Levator ani muscles (= pelvic diaphragm) are shown as light lines running deep to the pelvic viscera. The vaginolevator attachment is shown as a darker area. $\mathrm{AT}=$ arcus tendineus fasciae pelvis; $\mathrm{BC}=$ bulbocavernosus muscle; $\mathrm{CU}=$ compressor urethrae; $\mathrm{D}=$ detrusor muscle; $\mathrm{IC}=$ ischiocavernosus muscle LA $=$ levator ani muscles; PVL = pubovesical ligament (= pubovesical muscle); US = urethral sphincter; UVS = urethrovaginal sphincter; and VLA = vaginolevator attachment. Reprinted with permission from the American College of Obstetricians and Gynecologists, Obstet Gynecol 68:91, 1986.

TABLE I. Topography of Urethral and Paraurethral Structures* ${ }^{*}$

\begin{tabular}{|c|c|c|}
\hline $\begin{array}{l}\text { Approximate } \\
\text { location }^{a}\end{array}$ & $\begin{array}{l}\text { Region of the } \\
\text { urethra }\end{array}$ & Paraurethral structures \\
\hline $0-20$ & Intramural urethra & Urethral lumen traverses the bladder wall \\
\hline $20-60$ & Midurethra & $\begin{array}{l}\text { Sphincter urethrae muscle } \\
\text { Pubovesical muscle } \\
\text { Vaginolevator attachment }\end{array}$ \\
\hline $60-80$ & Urogenital diaphragm & $\begin{array}{l}\text { Compressor urethrae muscle } \\
\text { Urethrovaginal sphincter muscle }\end{array}$ \\
\hline $80-100$ & Distal urethra & Bulbocavernosus muscle \\
\hline
\end{tabular}

*Smooth muscle of the urethra was not considered.

${ }^{a}$ Expressed as a percent of total urethral length.

TReprinted with permission from the American College of Obstetricians and Gynecologists, Obstet Gynecol 68:91, 1986.

attached to them by the fibers of the perineal membrane (= urogenital diaphragm). It is within this area that the lower portion of the striated urogenital sphincter lies. Here, some fibers of the urethra's skeletal muscle pass posteriorly to end near the ischiopubic rami as the compressor urethrae and in the wall of the vagina as the urethrovaginal sphincter muscles, respectively. Finally, the distal most fifth of the urethra is formed by a fibrous nozzle, in the region where the urethra passes between 
the heads of the bulbocavernosus muscle. Although this external genital muscle lies adjacent to the urethra at this level it is unlikely that its position would allow it to influence urethral function. In this area the urethral wall is devoid of significant smooth or skeletal muscle and seems to exist to aim the urinary stream.

\section{STRUCTURES WHICH MAY INFLUENCE SPHINCTERIC FUNCTION BY CONSTRICTING THE LUMEN OF THE VESICAL NECK OR URETHRA}

The level of continence in the normal individual lies at the vesical neck, which in our observations occupies approximately the first $15 \%$ of the length of the urethral lumen. Here the urethra passes through the wall of the bladder and is surrounded by its musculature. Although this region is sphincteric in function, there is no true circularly disposed smooth muscle sphincter encircling the lumen here [Woodburne, 1968; Griffiths, 1891]. There is, however, a characteristic, smooth muscle in this area, composed of small fibers which is unlike the large bundles of the detrusor in the bladder dome [Huisman, 1983; Gosling, 1985] (Fig. 3). This muscle is morphologically different from the other muscle of the detrusor in having finer muscle bundles with less distinct separations. This has been called the trigonal ring by Huisman [1983] and the vesical neck musculature by Gosling [1985]. This region has a rich adrenergic nerve supply [Kluck, 1980]. It seems that this is likely the tissue which responds to alpha adrenergic stimulation and increases the muscle tone in this region.

Some of the smooth muscle fibers of the superficial trigone continue caudally within the urethra as the smooth muscle of the urethra, and have both an inner longitudinal layer as well as a thin circular outer layer [Krantz, 1951; Huisman, 1983]. In addition to these actively contractile elements, Woodburne [1968] has found that there is a considerable amount of elastic tissue within the region of the vesical neck which may assist in keeping the vesical neck closed.

The submucosal blood vessels which lie under the urethral mucosa are more numerous than would be needed to supply the minimal metabolic requirements of this region [Berkow, 1953]. In that intraurethral pressure falls when the pelvic vasculature is occluded [Rud et al., 1980], it seems possible that these vessels, by raising intraluminal pressure, might influence continence. Huisman [1983] has made a specific study of this vasculature and found a region of the submucosal vascular plexus which is prominent in the proximal urethra, $0.5 \mathrm{~cm}$ below the vesical neck and extending for approximately $1 \mathrm{~cm}$ downward. It contains specialized arteriovenous anastomoses which might allow this vascular system to assist in urethral closure by filling the venous sinuses under more arterial pressures. Direct measurements, however, substantiating this phenomenon are lacking.

As the urethra emerges from the wall of the bladder, it enters a region where it is surrounded by the striated urogenital sphincter muscle [Oelrich, 1983] (Figs. 4,5). This mass of striped muscle has two portions which are continuous with one another, and are separable only in their fiber direction and destination. The description of this muscle by Oelrich [1983] has clarified the confusion about this area which has arisen from the many, sometimes conflicting descriptions and illustrations of this region.

The more proximal part of this mass of skeletal muscle is the striated urethral sphincter (sphincter urethrae). This is a group of circularly oriented skeletal muscle fibers which surround the urethral smooth muscle coat. They are incomplete in the ventral aspect of the urethral wall, especially in older specimens, and the quantity of 


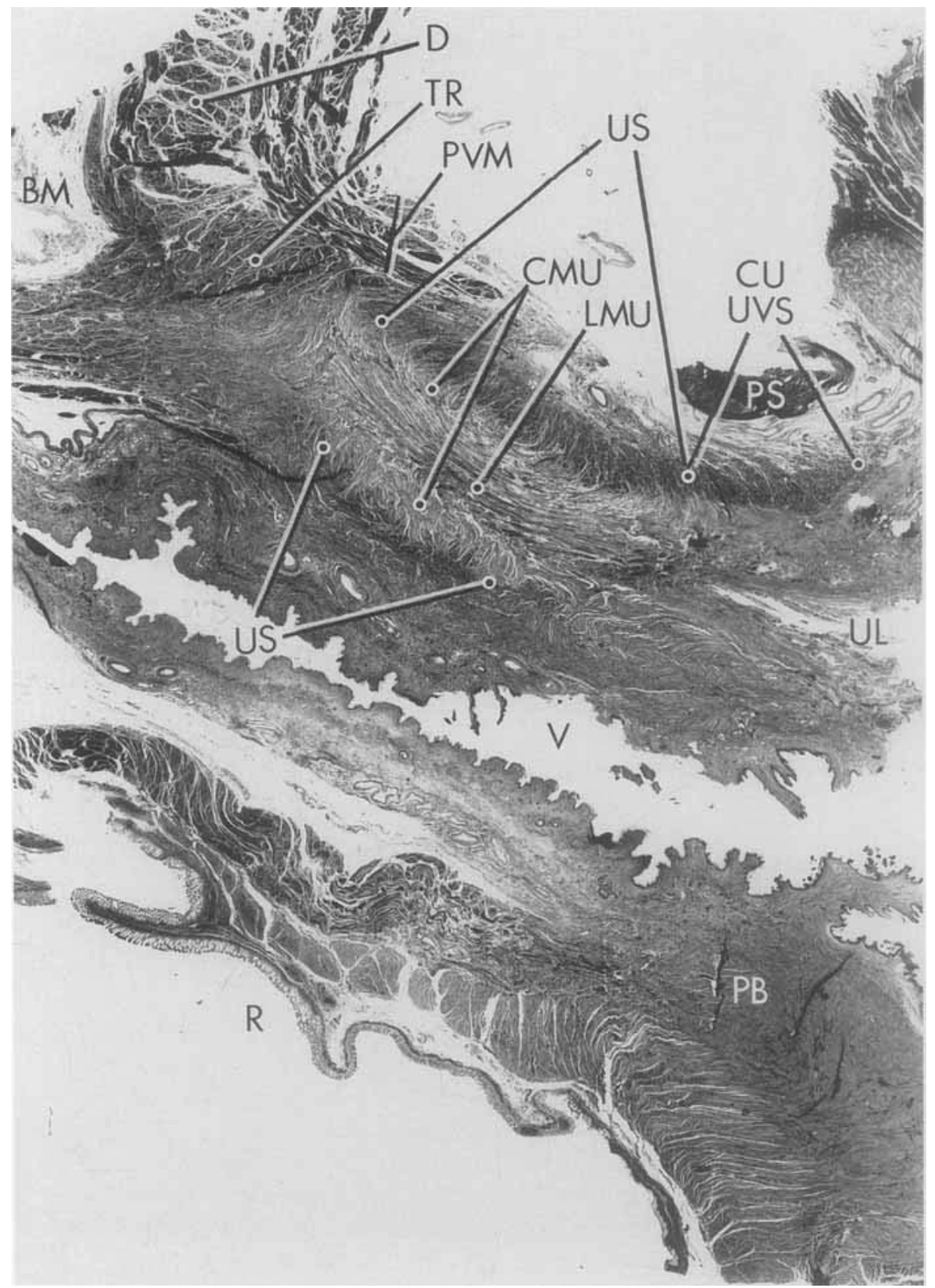

Fig. 3. Sagittal section from a 29-year-old cadaver, cut just lateral to the midline and not quite parallel to it. The section contains tissue nearer the midline in the distal urethra where the urethral lumen can be seen than at the vesical neck. $\mathrm{BM}=$ bladder mucosa; $\mathrm{CMU}=$ circular smooth muscle of the urethra; $\mathrm{CU}=$ compressor urethrae; $\mathrm{D}=$ detrusor muscle; $\mathrm{LMU}=$ longitudinal smooth muscles of the urethra; $\mathrm{PB}=$ perineal body; $\mathrm{PS}=$ pubic symphysis; $\mathrm{PVM}=$ pubovesical muscle; $\mathrm{R}=$ rectum; $\mathrm{TR}=$ trigonal ring; UL = urethral lumen; US = urethral sphincter; UVS = urethrovaginal sphincter; and V = vagina. Reprinted with permission from the American College of Obstetricians and Gynecologists, Obstet Gynecol 68:91, 1986. 

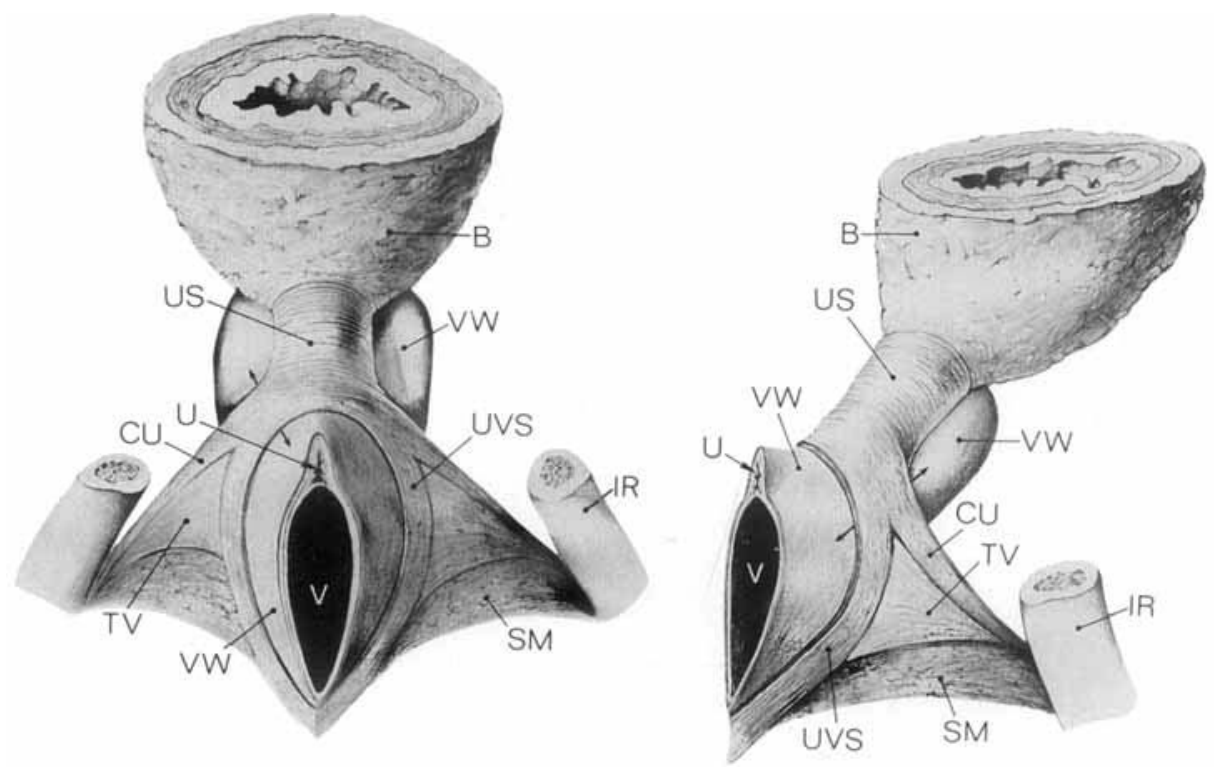

Fig. 4. The striated urogenital sphincter. $\mathrm{B}=$ bladder; $\mathrm{CU}=$ compressor urethrae, $\mathrm{IR}=$ ischiopubic ramus; $\mathrm{SM}=$ smooth muscle; $\mathrm{TV}=$ transverse vaginal muscle; $\mathrm{U}=$ urethra; $\mathrm{US}=$ sphincter urethrae; UVS = urethrovaginal sphincter; $\mathrm{V}=$ vagina; $\mathrm{VW}=$ vaginal wall. Reprinted with permission from Alan R. Liss, Inc., Anat Rec 205:223, 1983.

muscle varies considerably in its development. It extends from $18 \%$ to $64 \%$ of urethral length [DeLancey, 1986]. At the distal (caudal) end of the sphincter it blends with the second portion of the striated urogenital sphincter, that portion which lies at the level of the perineal membrane (=urogenital diaphragm).

In the region of the perineal membrane, some of the fibers of the striated urogenital sphincter extend beyond the limits of the urethra to end in the vaginal wall or at the ischiopubic ramus as previously described. This arrangement is found from $54 \%$ to $76 \%$ of urethral length.

The striated muscle of the urethra has a different composition than the muscle of the pelvic diaphragm, containing predominantly slow-twitch fibers [Gosling et al., 1981]. This makes it well suited for having a contribution to resting pressures, but its role in increasing urethral pressure during a cough remains controversial. There is a rise in urethral pressure which precedes a cough [Constantinou and Govan, 1982] which is presumably due to contraction of pelvic voluntary muscles, but whether this is due to the striated urogenital sphincter muscle or to the effect of some other muscle, such as the pelvic diaphragm, remains to be clarified.

In addition to these localized structures, there are also tissues found throughout most of the urethra's length without specific localization. The urethral mucosa is made up of stratified squamous epithelial cells at its outer portion, and becomes transitional epithelium in its upper portion. Its thickness and "turgor" may be important in maintaining mucosal coaptation. The smooth muscle of the urcthra extends throughout most of its length, and is composed of an inner longitudinal and 


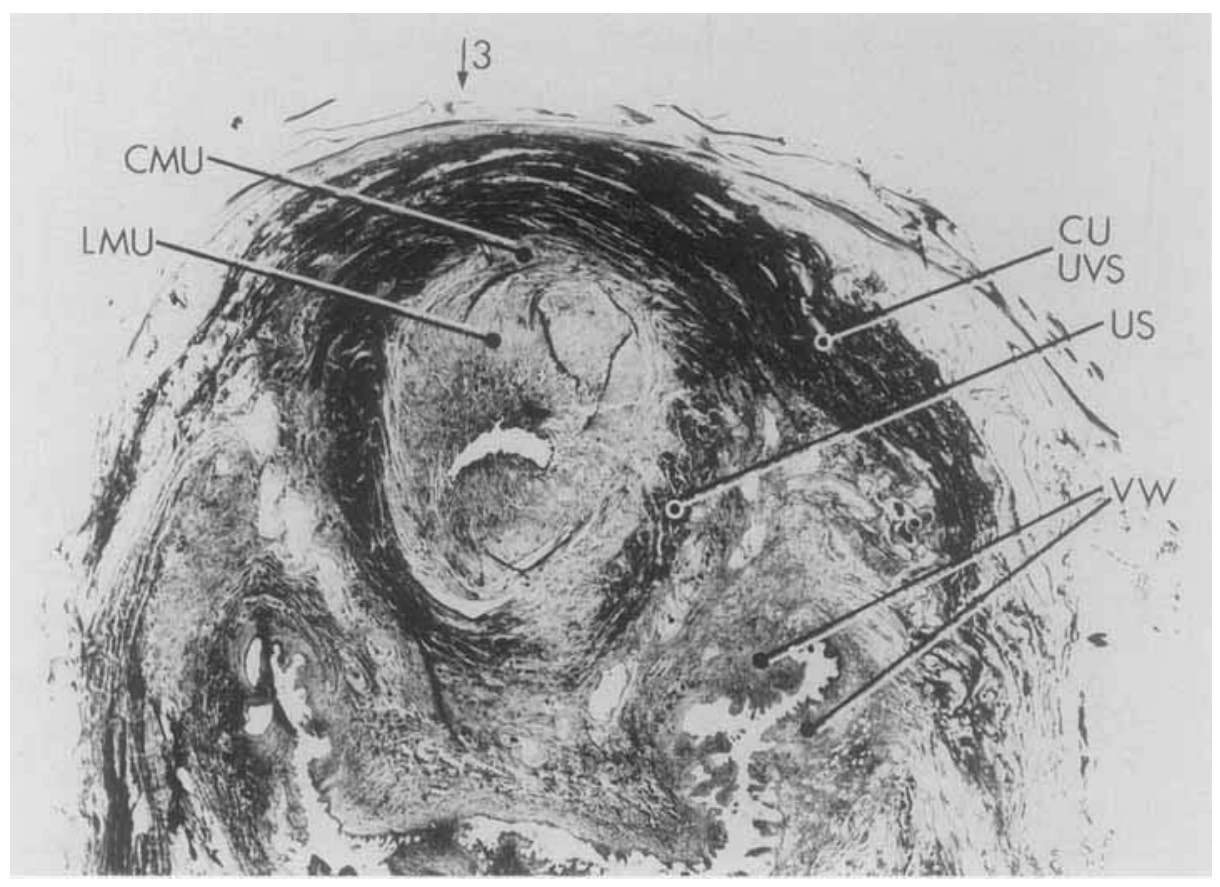

Fig. 5. Section taken at the junction of the striated muscle of the urethral sphincter and urogenital diaphragm. This cross section of the urethra was made with the left side of the cut being closer to the bladder than the right; therefore, only the right portion of the compressor urethrae and urethrovaginal sphincter are seen. CMU = circular smooth muscle of the urethra; LMU = longitudinal smooth muscle of the urethra; $\mathrm{CU}=$ compressor urethrae; UVS = urethrovaginal sphincter; US = sphincter urethrae; $\mathrm{VW}=$ vaginal wall; $\downarrow 3=$ the plane of section for Figure 3 . Reprinted with permission from the American College of Obstetricians and Gynecologists, Obstet Gynecol 68:91, 1986.

outer circular layers (Figs. 3,5). These layers begin in the trigone as has been discussed and it appears that this tissue contributes a significant portion of the overall maximum pressure of the urethra [Rud et al., 1980].

\section{FACTORS WHICH INFLUENCE THE VESICAL NECK AND URETHRA BY SUPPORT AND COMPRESSION}

The support of the proximal urethra has received considerable attention for its role in the development of stress urinary incontinence, and a loss of normal support certainly plays a role in the etiology of many of these patients. Terms such as "pubo-urethral" ligament, which have been applied to the urethral supports give the impression that the urethra is fixed to the pubic bones by inert ligaments. Observation of the upper urethra and vesical neck, however, reveal that they are quite mobile, and that their position is under voluntary control [Jeffcoate and Roberts, 1952]. Radiographic studies show that the junction of the mobile upper urethra, and the fixed lower urethra occurs at the $56 \%$ of anatomic urethral length [Westby et al., 1982], an area which these authors feel represents entry of the urethra into the urogenital diaphragm (=perineal membrane), a location which is confirmed by topographic 
analysis [DeLancey, 1986]. The primary support of the critical area of the urethra in terms of stress incontinence then lies above this level in the proximal urethra.

In the midurethra, there are two groups of fibers which run from the region of the vesical neck toward the pubic bones and surrounding structures of the pelvic wall, which might influence the position or function of the vesical neck: one is the pubovesical muscles (also called pubovesical ligaments), the other, the "urethral supports.",

The pubovesical ligaments (or muscles) are paired bands of smooth muscle which originate from the detrusor muscle at the level of the vesical neck and terminate near the lower border of the pubic bones in the arcus tendineus fascia pelvis (Figs. 3, 6). These muscles seem appropriately situated to pull the vesical neck anteriorly at the onset of micturition as has been observed [McGuire, 1983; Power, 1954].

In an earlier publication, the author named these fibers the pubo-urethral ligaments following previous precedents which considered that this term, and the term pubovesical ligaments (= pubovesical muscles) were synonymous. Some of our recent studies, however, suggest that the tissues which are responsible for urethral support are different than the pubovesical ligaments [DeLancey, 1988]. This would explain why some authors [Wilson et al., 1983] have not found any difference between these superficial tissues, thought to be the "pubo-urethral ligaments," in normal patients and those with stress urinary incontinence.

The stronger tissues, which on dissection seem to support the urethra and explain its mobility, are an attachment of both the urethra and vagina to the fascial structures of the pelvic wall. This attachment is to the arcus tendineus fascia pelvis (ATFP) [White, 1912; Richardson et al., 1981]. The ATFP is a condensation of the superior fascia of the pelvic diaphragm and the obturator internus fascia and forms a band anchored to bone at either end, as it stretches from near the lower border of the pubic symphysis, to the ischial spine. By attaching bilaterally to this dense fibrous structure, the vagina and its surrounding connective tissue forms a sling which runs under the urethra and vesical neck in a position where it may support the urethra.

In addition, within the area from $23 \%$ to $60 \%$ of urethral length, the vagina attaches to the pelvic diaphragm (= levator ani muscles) [DeLancey, 1986]. This "vaginolevator attachment"' (Fig. 2) could be responsible for the observed voluntary control of the proximal urethral position, whereby relaxation of the pelvic diaphragm allows the urethra to rotate posteriorly and inferiorly [Jeffcoate and Roberts, 1952] at the onset of micturition, and by contraction of the muscle, the urethra can be elevated in order to arrest the urine stream [Muellner, 1951].

A number of investigators have observed that the pressures measured with microtransducer catheters vary depending on the direction in which the pressure sensitive window is directed. This would imply that the lumen of the urethra is acted upon by forces outside the urethra itself, since elements of the urethral wall would be expected to constrict its lumen in a way that would give rise to circularly symmetric forces. Factors outside the urethra, by pressing against its wall, could compress its lumen and might cause asymmetries in "pressure" recordings.

Constantinou [1985] has noted that pressures measured with the transducer pointed posteriorly are greater in the proximal urethra, while those measured with an anterior orientation predominate in the distal portion (Fig. 7A). Furthermore, he has observed that in patients with stress urinary incontinence there is a selective loss of the posteriorly measured pressures. The topographical observations described above 


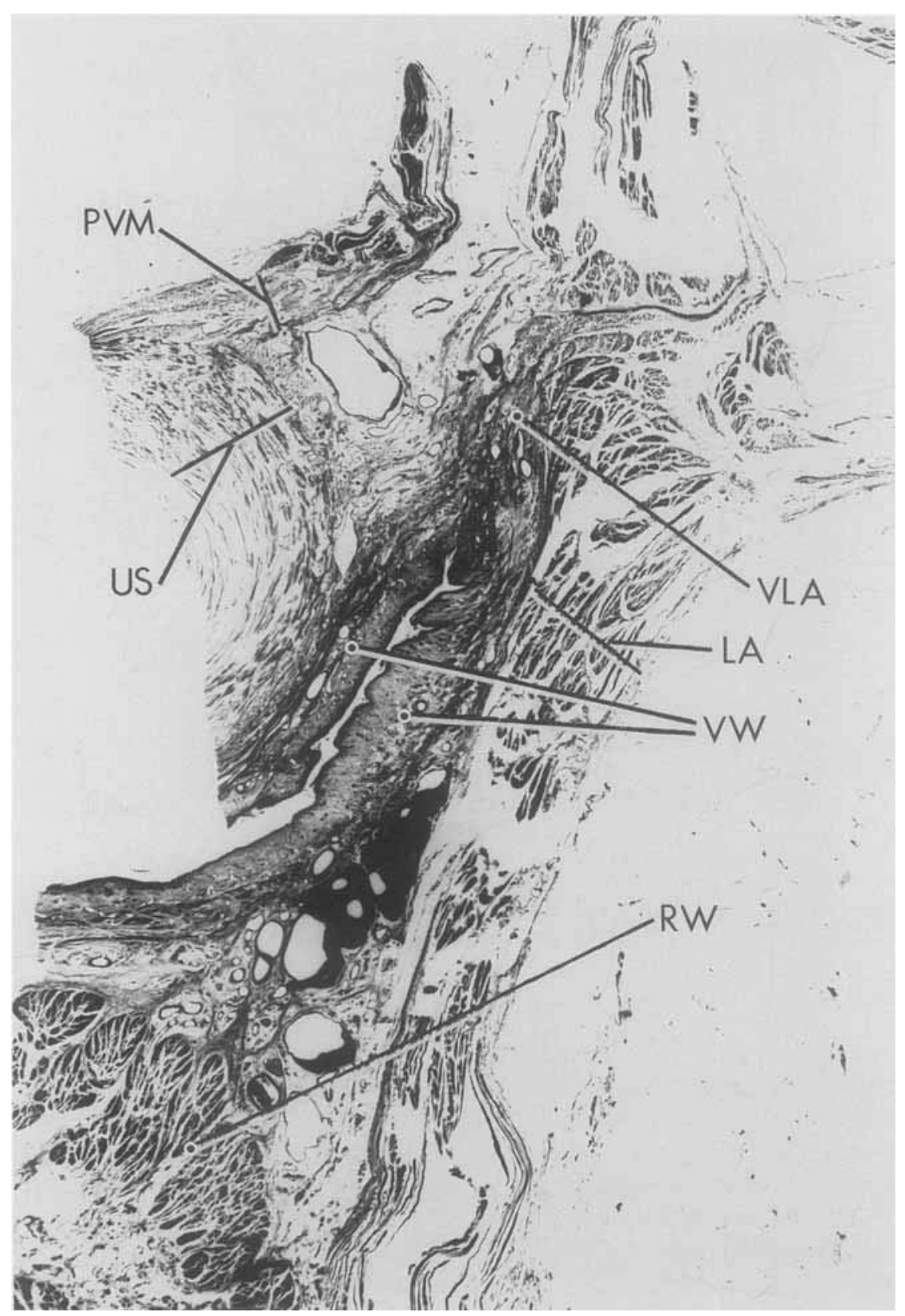

Fig. 6. A cross section taken from the left half of a pelvis which had been bisected just to the left of midline (16-year-old cadaver). PVM = pubovesical muscle; US = sphincter urethrae; VLA = vaginolevator attachment; $\mathrm{LA}=$ levator ani muscles; $\mathrm{VW}=$ vaginal wall; and $\mathrm{RW}=$ rectal wall. Reprinted with permission from the American College of Obstetricians and Gynecologists, Obstet Gynecol 68:91, 1986. 

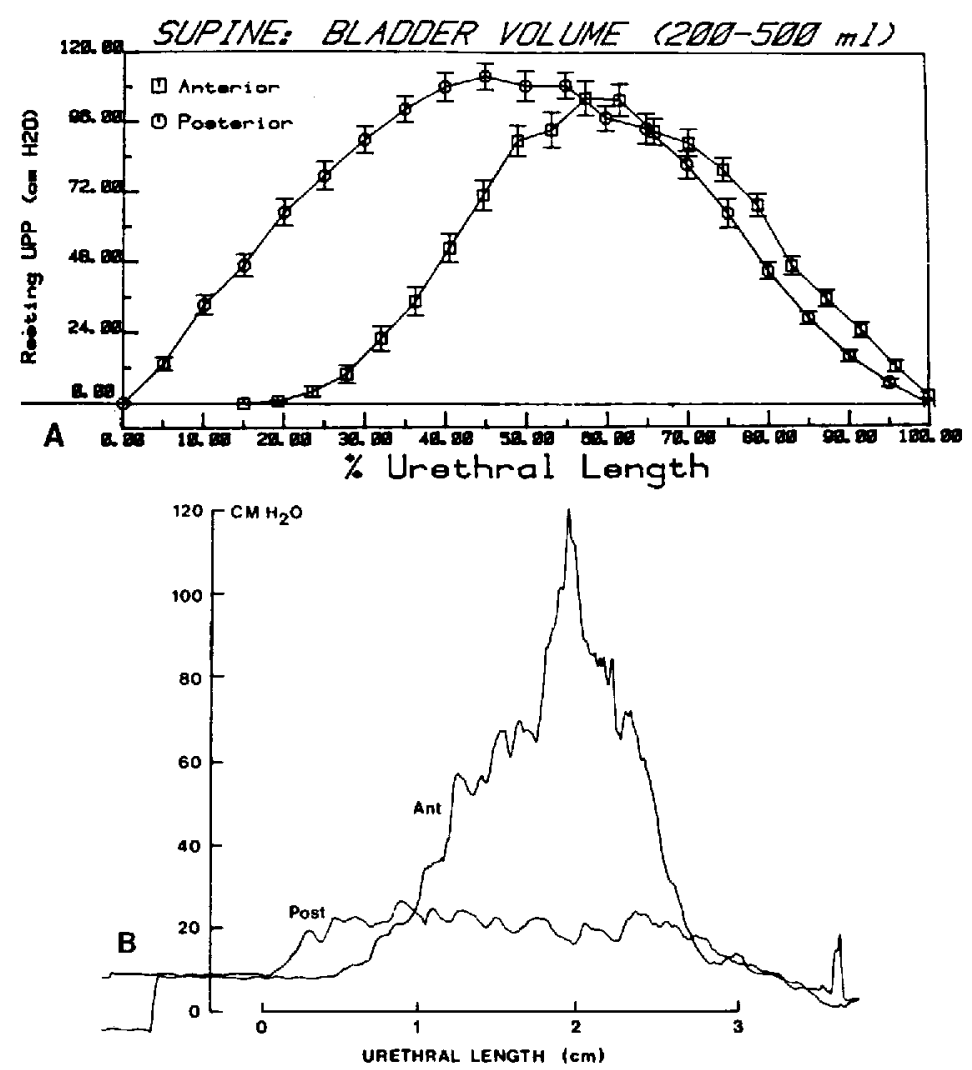

Fig. 7. A: Comparison of simultaneously measured anterior and posterior pressures in 17 normal volunteers from Constantinou [1985]. B: Anterior and posterior pressures in a patient with stress urinary incontinence showing the selective loss of posterior pressures. Reprinted with permission from W.B. Saunders Company, Urol Clin North Am 12:247, 1985.

would suggest that the posterior pressures lie in a region where the vagina might be pulled anteriorly against the urethra by its attachment to the levator ani (Fig. 6) (pubococcygeus, pelvic diaphragm), and that damage to these normal supportive attachments may be responsible for this lowering of measured pressures in this area in patients with stress urinary incontinence (Fig. 7B). The anatomical arrangements which might be responsible for these attachments are currently under further investigation by the author.

The finding that in the distal urethra, pressures are highest when the transducer is directed anteriorly might be explained by the presence of the compressor urethrae and urethrovaginal sphincter which arch over the anterior surface of the urethra in this region [DeLancey, 1986; Oelrich, 1983]. A downward movement of the anterior wall of the urethra in this region due to their contraction or resting tone may be responsible for higher anteriorly measured "pressures." Depression of the anterior urethral wall is sometimes visible with a urethroscope in the distal urethra when women are asked to tighten their pelvic muscles as if to arrest their urine stream, but this is not a universal finding. 


\section{CONCLUSION}

The correlation of physiologic measurements and anatomical findings enhances the value of each of these two observations when considered alone. By examining some of the morphologic features of urethrovesical anatomy in light of current urodynamic findings, the underlying structures which may be responsible for observed function can be better understood.

\section{REFERENCES}

Berkow SG (1953): The corpus spongiosum of the urethra: Its possible role in urinary control and stress incontinence in women. Am J Obstet Gynecol 65:346.

Constantinou CE (1985): Resting and stress urethral pressures as a clinical guide to the mechanism of continence in the female patient. Urol Clin North Am 12:247.

Constantinou CE, Govan DE (1982): Spatial distribution and timing of transmitted and reflcxly generated urethral pressures in healthy women. J Urol 127:964.

DeLancey JOL (1986): Correlative study of paraurethral anatomy. Obstet Gynecol 68:91.

DeLancey JOL (1988): The pubovesical ligament, a separate structure from the urethral supports (pubourethral ligaments). Neurourol Urodyn (in press).

Gosling JA (1985): The structure of the female lower urinary tract and pelvic floor. Urol Clin North Am 12:207.

Gosling JA, Dixon JS, Critchley HOD, Thompson SA (1981): A comparative study of the human external sphincter and periurethral levator ani muscles. Br J Urol 53:35.

Griffiths J (1891): Observations on the urinary bladder and urethra. J Anat Physiol 25:549.

Huisman $A B$ (1983): Aspects on the anatomy of the female urethra with special relation to urinary continence. Contrib Gynecol Obstet 10:1.

Jeffcoate TNA, Roberts H (1952): Observations on stress incontinence of urine. Am J Obstet Gynecol 64:721.

Kluck P (1980): The autonomic innervation of the human urinary bladder, bladder neck and urethra: A histochemical study. Anat Rec 198:439.

Krantz KE (1951): The anatomy of the urethra and anterior vaginal wall. Am J Obstet Gynecol 62:374.

McGuire E (1979): Urethral sphincter mechanisms. Urol Clin North Am 6:39.

Muellner SR (1951): The physiology of micturition. J Urol 65:805.

Oelrich TM (1983): The striated urogenital sphincter muscle in the female. Anat Rec 205:223.

Power RMH (1954): An anatomical contribution to the problem of continence and incontinence in the female. Am J Obstet Gynecol 67:302.

Ricci JV, Lisa JR, Thom CH (1950): The female urethra. Am J Surg 79:499.

Richardson AC, Edmonds PB, Williams NL (1981): Treatment of urinary incontinence due to paravaginal fascial defect.' Obstet Gynecol 57:357.

Rud T, Anderson KE, Asmussen M, Hunting A, Ulmsten U (1980): Factors maintaining the intraurethral pressure in women. Invest Urol 17:343.

Westby M, Asmussen M, Ulmsten U (1982): Location of maximal intraurethral pressurc in the female subject as studied by simultaneous urethrocystometry and voiding urethrocystography. Am J Obstet Gynecol 144:408.

White GR (1912): An anatomical operation for the cure of cystocele. Am J Obstet Dis Women 65:286.

Wilson PD, Dixon JS, Brown ADG, Gosling JA (1983): Posterior pubo-urethral ligaments in normal and genuine stress incontinent women. J Urol 130:802.

Woodburne RT (1968): Anatomy of the bladder and bladder outlet. J Urol 100:474. 